The BMJ

\title{
Covid-19: What new variants are emerging and how are they being investigated?
}

\section{The new, more transmissible variant of SARS
of the virus being detected around the world.
Elisabeth Mahase
What do we know about the new variant
emerging from Brazil?}

This variant, known as P.1 or VOC202101/02 in the UK, was first detected in travellers from Brazil who arrived in Japan in January 2021. It involves 17 unique amino acid changes, three deletions, four synonymous mutations, and one $4 \mathrm{nt}$ insertion. It has several mutations that are known to be biologically important, including E484K and N501Y.

The N501Y mutation, which is also a feature of the English variant, ${ }^{1}$ has been linked to increased infectivity and virulence in mouse models. ${ }^{2}$ Meanwhile, the E484K mutation is thought to be associated with escape from the neutralising antibodies produced by the body against SARS-CoV-2. ${ }^{3}$ This mutation is present in the South African variant as well.

P.1 has not yet been detected in the UK, and travel bans have been put in place to try to prevent it reaching the country. There is, however, another variant from Brazil (known as VUI202101/o1 in the UK) which contains a small number of mutations that has been found in the UK. As of 14 January 2021, eight cases of this variant-which appears to be of less concern-have been confirmed. Public Health England (PHE) said the "spread and significance of this variant remains under investigation."

Susan Hopkins, PHE covid strategic response director, said, "For now, our advice following detection of a Brazilian variant in the UK remains the same, even though this is not the variant detected in Manaus with more mutations: the best way to stop the spread of the virus is to wash your hands, wear a face covering, and keep your distance from others. While in lockdown, it's important that we stay at home unless it's absolutely essential to go out."

\section{What do we know about the South African variant?}

The South African variant emerged around the same time as the English one, and has since been detected in at least 20 countries. Genomic data from South Africa suggested that the variant, known as 501Y.V2, quickly displaced other circulating lineages in the country as it appears to have a higher viral load and is therefore more transmissible. ${ }^{4}$ This variant shares similarities with the English and Brazilian variants in that it contains both the $\mathrm{N}_{501} \mathrm{Y}$ and E484K spike protein mutations.

\section{Do the current vaccines work against the Brazilian, English, and South African variants?}

The three main vaccines-Pfizer BioNTech, Moderna, and Oxford AstraZeneca-all target the spike protein of the virus, where these variants have mutations. Researchers are still fairly confident, however, that the vaccines will work against them-although they are not sure whether protection could be reduced-because the spike protein is so large that many mutations would be needed to completely escape. Studies are now underway to test whether the vaccines are effective against these new variants.

\section{Could the virus still mutate to escape the vaccines?}

In an interview with The BMJ, ${ }^{5}$ Andrew Pollard, who leads the Oxford vaccine clinical trials, said the crucial period will be when lots of people are vaccinated, as this will put the virus under a lot of pressure. "When that happens some viruses just can't compete against that immunity. Will it mutate instead? With this coronavirus we don't know the answer to that question yet, and that's why surveillance is going to be critical in the year ahead to make sure that we're not in a position where, at the point of population immunity, the virus escapes. And if it does, we need to know that, so that we can redesign the vaccines," Pollard said. He added that the Pfizer, Moderna, and Oxford vaccines are "relatively straightforward to redesign for a new variant.”

\section{Is there any link between the 0xford vaccine trials-carried out in Brazil and South Africa-and the new variants?}

Pollard doesn't think so. He told The BMJ, “The number of people in the vaccine trials is so small that it's unlikely that our efforts would put any pressure on the virus to drive it to select new variants. Most trials only have a few hundred people vaccinated in cities of hundreds of thousands or millions of people. I don't think vaccination has anything to do with new variants today."

He explained, however, that the variants may be arising in Brazil and South Africa because of high transmission (as many as $40-50 \%$ of people being infected) in populations living in crowded conditions. Pollard said, "In those settings, variants of the virus that emerge that are able to spread despite existing post-infection immunity will be selected. If that's the case, it doesn't necessarily mean that we're going to find ourselves in a position where vaccines don't 
work against hospitalisation or severe disease, but it may be more difficult to prevent milder disease and transmission. We need to monitor the situation carefully and work out the process that would be needed to make an adjusted vaccine, should the need arise."

\section{How is the UK monitoring and studying new variants?}

The Covid-19 Genomics UK (COG-UK) consortium is carrying out large scale and rapid whole genome sequencing of virus samples, which enables it to identify new variants. It currently provides $48 \%$ of the genomic data supplied to GISAID, a global initiative which carries out real time surveillance of the pandemic.

The G2P-UK National Virology Consortium has been launched to work with COG-UK to study how mutations may affect key outcomes, the transmissibility of variants, the severity of illness they cause, and their response to vaccines and treatments.

The group is headed up by Wendy Barclay, head of infectious disease and chair in influenza virology at Imperial College London. She told a Science Media Centre briefing that there were two variants in Brazil being watched-one that was picked up in some travellers into Japan, and the other which is more prevalent in Brazil at the moment. She added, "The sequences that are in the spike protein there, are in the spike protein receptor domain. Studies from other groups and our own are suggesting that they might impact the way that some people's antibodies can see the virus. It's important that we carry out this work now and carry it out carefully and in several different laboratories to really firm up those results, because they have big implications.”

\section{How will the new variants be investigated?}

G2P-UK co-lead Michael Malim from King’s College London said, "Once a sequence of interest is identified we'll be able to synthesise that spike gene and make virus particles in the laboratory. Then we'll test the sensitivity of that virus to inhibition of infection in laboratory models to a range of sera from vaccines and natural infection, and work out if there is a change. It would take about two to three weeks from knowing which sequence to focus on to having those results. So, pretty quickly, we would know where the variant, for example, could potentially break through vaccination.”

\section{Are countries collaborating as variants arise?}

A global surveillance system is something that the World Health Organization is working on, according to Barclay. She said, "A group like ours could play a role. Surveillance and update systems will require the basic biology. They need underpinning biology that will come from the studies that we, and other groups around the world, do. That will feed into the WHO draft plan for how we deal with this virus, which is going to be with us for the foreseeable future.”

1 Mahase E. Covid-19: What have we learnt about the new variant in the UK?BMJ2020;371:m4944. doi: 10.1136/bmj.m4944 pmid: 33361120

2 Rambaut A, Loman N, Pybus O, et al. Preliminary genomic characterisation of an emergent SARS-CoV-2 lineage in the UK defined by a novel set of spike mutations. December 2020 https://virological.org/t/preliminary-genomic-characterisation-of-an-emergent-sars-cov-2-lineagein-the-uk-defined-by-a-novel-set-of-spike-mutations/563.

3 Voloch CM, da Silva RF, Jrde Almeida LGP, et al. Genomic characterization of a novel SARS-CoV-2 lineage from Rio de Janeiro, Brazil.Medrxiv 2020.12.23.20248598 [Preprint]. 2020. www.medrxiv.org/content/10.1101/2020.12.23.20248598v1.full.pdf.

4 WHO. SARS-CoV-2 variants. 31 December 2020. www.who.int/csr/don/31-december-2020-sarscov2-variants/en.

5 Mahase E. How the Oxford-AstraZeneca covid-19 vaccine was made. BMJ2021;372:n86. doi: 10.1136/bmj.n86 pmid: 33436419 